?

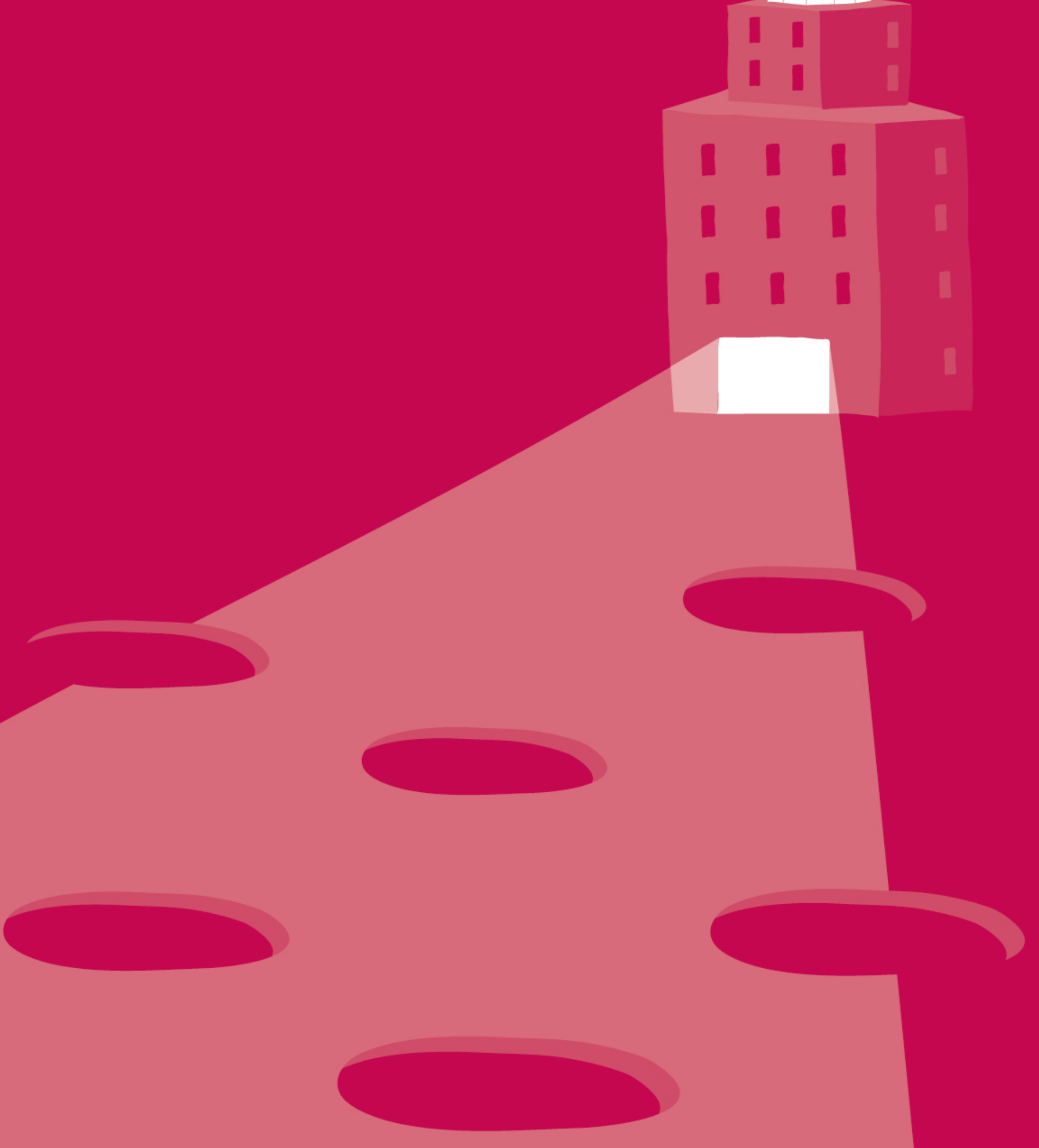




\section{A importância da comunicação de riscos para as organizações}

Alexandra Rinaldi

- Mestre em Sistema Integrado de Gestão pelo Senac

- Graduada em Jornalismo pelas Faculdades Integradas Alcântara Machado (FIAM-FMU)

- Jornalista da Assessoria de Comunicação Social da Fundacentro

- alexandra.rinaldi@fundacentro.gov.br

Dorival Barreiros

- Doutor em Engenharia pela Escola Politécnica da Universidade de São Paulo (Poli-USP)

- Professor do curso de Mestrado de Sistema Integrado de Gestão do Senac

- Pesquisador da Fundacentro

-dbarreiros@globo.com 
Resumo

A comunicação de risco é um tema complexo e abrangente ao envolver situações de risco, sejam eles decorrentes de ações humanas, naturais ou industriais. Este artigo tem como objetivo evidenciar a importância da comunicação de risco para as organizações e, ao mesmo tempo, apontar benefícios e limitações que as corporações encontram ao incorporarem o tema nos seus processos de gestão.

PALAVRAS-CHAVE: RISCO • COMUNICAÇÃO DE RISCO • GERENCIAMENTO DE RISCO

\section{Abstract}

Risk communication is a complex and encompassing theme, which involves situations of risk, whether from human, natural or industrial actions. This article has the purpose of showing the importance of risk communication for the organizations, while at the same time pointing out the benefits and barriers that corporations encounter when incorporating the theme with their risk management processes.

KEYWORDS: RISK • RISK COMMUNICATION • RISK MANAGEMENT

\section{Resumen}

La comunicación de riesgo es un tema complejo y amplio. Está ligada a situaciones de riesgo de diversa índole, derivadas de acciones humanas, causas naturales o actividades industriales. El objetivo de este artículo es evidenciar la importancia de la comunicación de riesgo para las organizaciones y, al mismo tiempo, apuntar los beneficios y limitaciones que las corporaciones encuentran al incorporar el tema a sus procesos de gestión.

PALABRAS CLAVE: RIESGO - COMUNICACIÓN DE RIESGO - ADMINISTRACIÓN DE RIESGO 
$\mathrm{O}$ s princípios da comunicação de risco são importante instrumento a ser incorporado à gestão organizacional a fim de melhorar a capacidade de diálogo das organizações com suas partes interessadas ${ }^{1}$, de modo a tornar possível a incorporação desses princípios ao processo de tomada de decisão sobre como os riscos devem ser gerenciados.

Ao se incorporar tais princípios no processo de tomada de decisão, contribui-se para que diferentes partes interessadas desenvolvam correta percepção a respeito da dimensão dos riscos existentes para, dessa forma, buscarem consenso a fim de compatibilizar interesses aparentemente divergentes.

A comunicação de risco é um tema interdisciplinar complexo pelo fato de ser abordado por diversas áreas do conhecimento, como, por exemplo, as várias modalidades da Engenharia, a Psicologia Social, a Sociologia, o Direito, entre outras que lhe conferem diferentes olhares. Sua abrangência é cada vez maior dentro das organizações. Questões relacionadas aos problemas decorrentes da gestão ambiental, da gestão da segurança e saúde no trabalho, de acidentes tecnológicos e mesmo as questões relacionadas ao risco do negócio da organização podem ser mais bem entendidas pelas partes interessadas graças à compreensão da importância da comunicação de risco.

Neste texto, comunicação de risco é entendida como

"um processo interativo de troca de informações e opiniões com as diferentes partes interessadas, compreendendo múltiplas mensagens sobre a natureza dos riscos e a maneira como são identificados, analisados e gerenciados." (Série Risk Management, 2005, p.14)

A comunicação de risco é uma das etapas do processo de gerenciamento de risco; tem uma dimensão técnica e deve ser avaliada no conjunto de ações e decisões que acontecem em um contexto social, razão pela qual se faz necessário buscar uma interação com as diferentes partes interessadas a fim de evitar que divergências sobre a percep-

1 De acordo com Barreiros (2004), partes interessadas são diferentes grupos internos ou externos à organização que são afetados diretamente pelo desempenho da gestão dos riscos e com poderes para exercer alguma influência sobre o processo de decisão das organizações a fim de modificar esse desempenho. Neste texto, as partes interessadas são as agências reguladoras, as empresas, técnicos especialistas, sindicatos de trabalhadores, sindicatos de empresários, comunidades e a mídia em geral. 
ção desses riscos possam desdobrar-se em situações que dificultem ainda mais a governabilidade organizacional.

De acordo com Renn (2006), gerenciamento de risco é um procedimento lógico e interativo mantido pela adoção sistemática de políticas, procedimentos e práticas organizacionais com o objetivo de estabelecer os contextos dos riscos, identificar, analisar, avaliar, tratar, monitorar e comunicar os riscos associados. O processo de gerenciamento de riscos gera informações que permitem ao tomador de decisão melhor compreender os riscos existentes e seus possíveis impactos, possibilitando às organizações alternativas para minimizar perdas e identificar oportunidades.

A partir dos anos 1980, aliada ao processo de gerenciamento de riscos, a comunicação de risco se consolida como um instrumento capaz de auxiliar o gestor a dar às partes interessadas maior transparência acerca do modo como as organizações lidam com as diferentes situações de riscos decorrentes de suas atividades.

Vários eventos podem justificar o interesse crescente das organizações por esse tema, tais como os acidentes ocorridos em Flixborough (1974), Seveso (1976), Three Mile Island (1979), Bhopal (1984) e Chernobyl (1986), que tiveram grande visibilidade pública na mídia internacional em razão dos impactos provocados em pessoas e no meio ambiente.

Desde então, esse tema vem ganhando importância entre os tomadores de decisão de entidades públicas e privadas, que perceberam nessa iniciativa um instrumento de gestão apropriado para dialogar com as partes interessadas a respeito de situações de riscos que poderiam vir a ameaçar ou comprometer a saúde e a integridade física das pessoas e/ ou o meio ambiente.

Com o desdobramento desses eventos, diferentes partes interessadas passaram a exigir novas regulamentações por parte dos poderes públicos e, das organizações, maior transparência na maneira como os riscos decorrentes de suas atividades deveriam ser gerenciados.

Sobre os diferentes desdobramentos intrínsecos ao tema, Sandman (1987, p. 21) restringe sua importância no contexto do gerenciamento de riscos e afirma:

"os riscos que o matam não são necessariamente aqueles que o aborrecem ou amedrontam. Para preencher a lacuna entre esses dois tipos de risco, os gestores responsáveis pelo gerenciamento de risco começaram a utilizar a comunicação de risco a fim de poder evidenciar as diferentes vulnerabilidades existentes".

Como parte do processo do gerenciamento de riscos, Cvetkovich e Lofstedt (1999) observam que a comunicação de risco é um instrumento de gestão que auxilia as organizações a compartilharem seus processos de decisão com as partes interessa- 
das direta ou indiretamente afetadas pela existência dos riscos decorrentes de sua atividade.

Desde seu surgimento à atual realidade, as experiências organizacionais apontam para dificuldades em adequar e incorporar a comunicação de risco ao processo de gerenciamento de riscos. Essas dificuldades decorrem da falta de transparência daquilo que se quer comunicar e de como e quando comunicar. Acrescenta-se a isso a dificuldade de compatibilizar os diferentes interesses das organizações com as expectativas das diversas partes interessadas envolvidas.

Em decorrência das dificuldades de compreensão sobre a importância da comunicação de risco em diferentes contextos, muitas organizações enfrentam momentos delicados para justificar a implementação de projetos e explicar emergências decorrentes de acidentes provocados por situações de riscos presentes em seus processos produtivos.

Isso não significa que, se essas organizações tivessem incorporado os princípios da comunicação de risco aos seus processos de tomada de decisão, poderiam ter evitado tais acidentes. Enfatiza-se apenas que a incorporação desses princípios poderia contribuir para uma melhor compreensão desses eventos, a fim de que eles se mantivessem dentro da governabilidade organizacional.

São inúmeros os exemplos em que uma estratégia inadequada de comunicação de risco provoca desdobramentos que levam muitas organizações a perder totalmente sua capacidade de agir na liderança e na decisão sobre o que fazer após a ocorrência de um evento.

Cada vez mais, as organizações se vêem obrigadas a incorporar em suas estratégias iniciativas voluntárias que exigem delas uma maior adesão a princípios que possam indicar às diferentes partes interessadas que sua atuação é ética e socialmente responsável ao lidar com riscos.

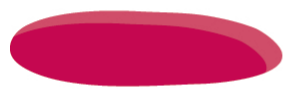


O exemplo mais interessante vem das indústrias químicas que, desde 1986, vêm incorporando o programa denominado Responsible Care® ou Atuação Responsável como forma de melhorar o gerenciamento de seus riscos nesse tipo de atividade.

A implementação dessa iniciativa pelas indústrias químicas vem contribuindo para tornar mais eficazes seus mecanismos de controle dos riscos e, ao mesmo tempo, melhorar a capacidade de diálogo e a sua imagem junto às partes interessadas.

Nesse mesmo contexto de aplicação voluntária, o Programa das Nações Unidas para o Meio Ambiente (Pnuma), lançou, em 1988, o Apell (Alerta e Preparação de Comunidades para Emergências Locais), que auxilia as organizações quanto à gestão dos riscos. Ainda em 1988, a Associação Brasileira da Indústria Química (Abiquim) incumbiu-se de implantar o Apell no Brasil, como um instrumento para elaboração de planos de emergência a fim de aumentar a coordenação no atendimento a acidentes e melhorar o diálogo entre a indústria e a população.

Embora muitas organizações venham se esforçando para incorporar a comunicação de risco em seus programas de gestão de maneira voluntária, muitas delas agem e são obrigadas, por requisitos legais, a informar às partes interessadas sobre seus riscos. Entre os exemplos estão o programa Direito-de-Saber (Right-to-Know), implementado nos Estados Unidos, e o programa Comunicação em Situações de Emergência, implantado no Brasil pela Companhia de Tecnologia de Saneamento Ambiental (Cetesb).

Em julho de 2002, nos Estados Unidos, foi implantada a lei Sarbanes-Oxley, nome dado em homenagem aos seus autores, os senadores Paul Sarbanes e Michael Oxley. Essa lei busca garantir a criação de mecanismos de auditoria e segurança confiáveis nas empresas, de maneira a reduzir os riscos relativos aos negócios e garantir a transparência na gestão das organizações.

\section{O papel da mídia no processo de comunicação de riscos}

A mídia desempenha um papel fundamental no processo de comunicação de riscos, auxiliando na formação da percepção da opinião pública a respeito das dimensões dos riscos e na maneira como deveriam ser gerenciados pelas organizações. Entretanto, quando se trata de divulgar informações sobre riscos, a mídia pode exemplificar ou exacerbar o conteúdo das informações com desdobramentos sérios sobre a percepção que as partes interessadas formam a respeitos dos riscos existentes.

Os erros em interpretar dados, as disputas entre os diferentes veículos de comunicação, a cobertura prematura de informações científicas e, em algumas situações, o sensacionalismo demasiado da mídia culminam em má interpretação por parte do públi- 
co, que incorpora uma percepção equivocada a respeito da possibilidade da ocorrência de um determinado evento (COVELLO et al., 1987).

Em 1989, durante a apresentação do programa norte-americano 60 minutos (60 minutes), o âncora do programa informava em rede nacional que os agricultores estavam utilizando pesticidas carcinogênicos nas maçãs para que elas ficassem com tamanho e aparência maiores. Como resultado, a notícia gerou histeria na população e fez com que a indústria e os agricultores assumissem um prejuízo de cem milhões de dólares. Nesse caso, a precipitação da mídia foi resultado da pressão exercida pelos ambientalistas para que os agricultores banissem o uso de pesticidas no cultivo das maçãs.

$\mathrm{Na}$ ocasião dessa reportagem veiculada pelo programa 60 minutes, o jornal Los Angeles Times publicava matéria informando a população sobre a decisão das indústrias de banir o uso de pesticidas. A esse respeito, os autores Cannell e Otway (1988, p. 170) destacam:

"As inadequações sobre a comunicação de risco emergem não por serem intrinsecamente dificeis de informar o público sobre a natureza e as conseqüências de um risco tecnológico. A comunicação de riscos não pode ser vista como uma forma de resolver conflitos, os quais, inevitavelmente, emergem da sociedade quanto à escolha e implementação de tecnologias".

Embora em muitas situações exista uma exacerbação por parte da mídia para informar situações de riscos que possam vir a comprometer a saúde e/ ou a integridade física das pessoas e do ambiente, é importante destacar a crescente preocupação da mídia em incorporar às suas coberturas jornalísticas textos cada vez mais fundamentados em evidências que possam levar informações sem vieses. Como exemplo, podemos mencionar a criação de editorias voltadas à ciência, saúde e meio ambiente, notadamente nos jornais $O$ Estado de S. Paulo, Folha de S. Paulo e Jornal do Brasil, e as revistas segmentadas em saúde, segurança e meio ambiente.

\section{Benefícios da comunicação de riscos no processo de gerenciamento de riscos}

A incorporação dos princípios da comunicação de riscos ao processo de tomada de decisão pelas organizações pode contribuir para que as partes interessadas encontrem meios que permitam diálogo e consenso que levem à convergência de interesses a princípio inconciliáveis.

Em determinadas circunstâncias, a percepção que o público tem a respeito de questões que envolvam riscos ao meio ambiente ou riscos à saúde tende a ser equivocada em função da maneira como é informado ou tem acesso às informações a respeito dessas situações. 


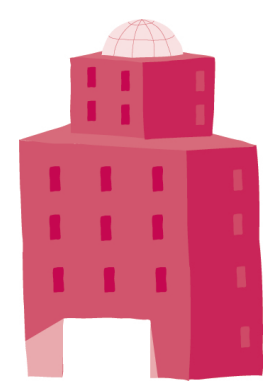

A comunicação de risco deve ser parte da estratégia de comunicação das organizações e, portanto, considerar o ponto de vista das diferentes partes interessadas ajuda a melhorar a qualidade na gestão de riscos.

Além disso, o processo de comunicação de risco tem auxiliado os acionistas a alcançar maior eficácia nos objetivos da comunicação, subsidiando-os nas decisões estratégicas do negócio, permitindo-lhes rever estratégias e engajando-os no exercício do diálogo mútuo, minimizando conflitos com as diversas partes interessadas (COVELLO et al., 2001).

Para as organizações, a boa comunicação é essencial para o desenvolvimento de uma cultura em que as dimensões positivas e negativas dos riscos sejam reconhecidas e avaliadas. A comunicação dos riscos ajuda a organização a estabelecer sua atitude em relação a eles (Australian Standards-New Zealand Standards 4360:2004).

Numa abordagem mais institucional, a comunicação de riscos deve ser um processo de comunicação e não deve se restringir simplesmente a mensagens sobre riscos, mas, acima de tudo, a uma afirmação sobre segurança. Comunicar riscos, políticas, estratégias, programas e iniciativas requer maturidade organizacional, caracterizando-se como um desafio permanente nas empresas.

\section{Limitações organizacionais para a efetiva comunicação dos riscos}

Em detrimento da própria complexidade de se estabelecer a comunicação de riscos, bem como de se identificar e envolver as diferentes partes interessadas e alinhar suas diferentes percepções, as organizações se vêem confrontadas com fatores políticos que, em sua grande parte, advêm do clima interno ou da sua própria política organizacional. Nesse sentido, Wiedemann (1999) observa que as micropolíticas existentes nas organizações decorrem, em grande parte, das diferenças de interesses entre essas partes interessadas, disputas de poder internas e da ausência de transparência em compartilhar suas ações. 
Da mesma maneira que a política interna influencia negativamente o resultado das organizações, a política externa revela-se outro ponto de descontentamento. Representadas pelo governo e pelas agências reguladoras, essas instituições têm um papel social importante, pois são elas que devem agir em favor do interesse público. Para as organizações, os fatores políticos são vistos como intrusivos na medida em que podem impactar nos seus resultados.

Além disso, quando o processo de tomada de decisão no setor público ou privado deixa de envolver as partes interessadas, os desdobramentos com relação às estratégias para a gestão do risco podem ficar comprometidos.

Essas posições antagônicas entre a política interna e a externa expõem as organizações a um emaranhado de conflitos, culminando em processos judiciais, atrasos na produção, boicotes, conspirações e reação negativa da mídia, trazendo como conseqüências o comprometimento da imagem corporativa e a possibilidade da perda de governabilidade sobre como gerenciar seus eventos.

\section{Considerações Finais}

Os modelos de gerenciamento de riscos atualmente utilizados no Brasil reforçam a importância do processo da comunicação de risco e oferecem grande oportunidade e auxílio aos gestores na compreensão de todo o processo de gestão. Contudo, as formas de implementação e de adoção dessas iniciativas ainda são fragilizadas e incipientes na realidade brasileira.

Em sua maior parte, os modelos de gerenciamento de riscos foram propostos por países europeus e outros como Canadá, Estados Unidos, Nova Zelândia e Austrália.

Exceto entre as grandes organizações privadas, que têm em seus quadros pessoal especializado capaz de evidenciar a importância do processo de comunicação de risco para as iniciativas de gerenciamento de riscos, a situação ainda se mostra incipiente nas iniciativas do poder público.

$\mathrm{Na}$ literatura nacional, identificou-se uma enorme lacuna de pesquisas que pudessem auxiliar as organizações a compreender esse processo de comunicação de riscos.

Dada a importância, a complexidade e a interdisciplinaridade do tema, a comunicação de risco deve estar inserida em outras disciplinas. Na Engenharia, representada aqui por gestores e especialistas em gestão de riscos. Na Psicologia, ao abordar os aspectos intuitivos e cognitivos voltados para a compreensão da percepção do risco. $\mathrm{Na}$ Comunicação Social, por meio dos cursos de jornalismo ambiental e jornalismo científico, além do sólido conhecimento de Relações Públicas e de sua importância no re- 
lacionamento com as partes interessadas. Por último, nos cursos de Direito, pelo arcabouço jurídico em leis e regulamentos voltados à saúde, segurança e meio ambiente. Na Pedagogia, a comunicação de risco também poderá dar importante contribuição à medida que forme cidadãos preparados e conscientes do seu papel na sociedade, especialmente frente aos novos riscos tecnológicos.

Na prática, uma série de fatores de caráter social, ético, organizacional, educacional, cultural e governamental impede que a comunicação de risco seja implementada de maneira efetiva e obrigatória nas organizações. Além disso, grande parte dos trabalhos científicos está voltada a compreender a comunicação ambiental e a comunicação em saúde, mas não a comunicação do ponto de vista da própria gestão dos riscos. A principal contribuição da comunicação de risco é que o tema, embora venha sendo paulatinamente discutido e incorporado nas grandes organizações, pode auxiliá-las na construção da confiança e da credibilidade, a partir do momento em que incorpore a comunicação de risco em todas as etapas que compreendem o processo de gerenciamento de riscos. Uma vez que divulgar informações sobre riscos envolve uma série de julgamentos científicos, a comunicação de risco oferece a oportunidade de "traduzir" aquilo que seja de desconhecimento público. E, nesse processo, ela não terá somente uma participação passiva, mas também ativa, na medida em que sua função é estabelecer o diálogo de mão dupla, informando e recebendo a opinião das partes interessadas.

A despeito de todas as limitações que movem a comunicação de risco nas organizações, ela pode dar importante contribuição aos processos de gestão e, conseqüentemente, aos gestores e especialistas. Para tanto, é necessário que as organizações tenham real consciência sobre a importância de informar a sociedade sobre seus riscos, mas, sobretudo, priorizar recursos aos gestores na adoção de políticas organizacionais em comunicação de risco.

Em países democráticos, a adoção do Right-to-Know e do Freedom of Information Act aconteceu de forma voluntária e não compulsória e teve por objetivo atender às expectativas das partes interessadas com relação ao processo de comunicação de risco.

Para isso, impõe-se ao poder público o desafio de avançar com novas medidas e mecanismos legais que auxiliem as organizações a informarem seus riscos, como, por exemplo, a adoção de uma política nacional de gerenciamento e comunicação dos riscos tecnológicos.

Para concluir, ainda que as audiências públicas tenham como fundamento a prática da comunicação de riscos e da legitimidade social ao envolver a população nas questões voltadas ao meio ambiente, a discussão acerca dos riscos tecnológicos deve ser ampliada a fim de contribuir para a formação popular e para a cultura da prevenção. 


\section{Referências}

AUSTRALIAN STANDARDS-NEW ZEALAND STANDARDS. AS-NZS 4360:2004. Risk Management Guidelines, 2004.

BARREIROS, Dorival. Gestão da segurança e saúde no trabalho: estudo de um modelo sistêmico para as organizações do setor mineral. Tese (Doutorado em Engenharia de Minas) - Escola Politécnica da USP. São Paulo: Universidade de São Paulo, 2004.

CANNELL, William; OTWAY, Harry. Audience perspectives in the communication of technological risks. Futures 20 (5), 519-531, 1988.

COVELLO, Vincent et al. Communicating scientific information about health and environmental risks: problems and opportunities from a social and behavioral perspective. 1987.

Risk communication, the west Nile virus epidemic, and bioterrorism: responding to the communication challenges posed by the intentional or unintentional release of a pathogen in an urban setting. Journal of Urban Health, Oxford, v.78, n.2, p. 382-391, 2001.

CVETKOVICH, George; LOFSTEDT, Ragnan (eds.). Social trust and the management of risk. London: Earthscan, 1999.

KRIMSKY, Sheldon; PLOUGH, Alonzo. Environmental hazards: communicating risks as a social process. Westport, Connecticut: Auburn House, 1988.

RENN, O. Risk governance: towards an integrative approach. International Risk Governance Council. 2006.

SANDMAN, Peter. Risk communication: facing public outrage. Environmental Protection Agency Journal. Nov. p. 21-22. 1987.

SÉRIE RISK MANAGEMENT. Gestão de riscos: diretrizes para a implementação da AS/NZS 4360. São Paulo: Risk Tecnologia Editora, 2005. 91 p.

WIEDEMANN, Peter et al. Risk communication for companies: thriving and surviving in an age of risk. 1999.
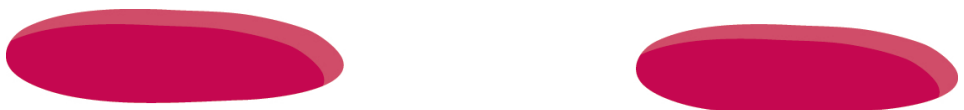